\title{
Meteorolojik Akıș Katsayısının Bulanık SMRGT Yöntemi ile Belirlenmesi: Murat Havzası Örneği
}

\section{Determining Meteorological Flow Coefficient by Using Fuzzy SMRGT Method: An Example for Murat Basin}

\section{Fatih Şevgin ${ }^{1}$, Z. Fuat Toprak ${ }^{2 *}$}

${ }^{1}$ Muş Alparslan Üniversitesi, Teknik Bilimler MYO, Muş, f.sevgin@alparslan.edu.tr

2 Dicle Üniversitesi, İnşaat Mühendisliği Bölümü, Diyarbakır, toprakzf@ dicle.edu.tr

\begin{tabular}{l}
\hline MAKALE BİLGİLERİ \\
\hline Makale geçmişi: \\
Geliş: 21 Aralık 2020 \\
Düzeltme: 13 Ocak 2021 \\
Kabul: 18 Ocak 2021 \\
\hline Anahtar kelimeler: \\
Taşkın debisi, Akış katsayısı, \\
Bulanık mantık, Modelleme, \\
Bulanık SMRGT
\end{tabular}

Doi: $10.24012 /$ dumf. 844325

\begin{abstract}
ÖZET
Taşkınlar, küresel iklim değişikliğinin söz konusu olduğu günümüzde en önemli hidrolik ve hidrolojik problemlerden biri haline gelmiștir. Așırı kentleșme, beton yapılar ve asfalt yollar gibi geçirimsiz yüzeylerin artması taşkın debisini artıran en önemli etmenlerdir. Geçirimsiz tabakalar yüzeyin veya havzanın akış katsayısını yükseltmektedir. Bu durum yer altı suyunun kısmen kaybına neden olurken diğer taraftan dere yataklarının taşıma kapasitesinin üstünde bir akıma neden olmaktadır. Böylece taşkın hadisesi kaçınılmaz olmakla beraber bunun sonucunda ise hem can hem de mal kaybı meydana gelmektedir. Akıșa geçen debinin önceden doğruya en yakın şekilde tahmin edilmesi olası can ve mal kaybını önlemek veya en azından minimum seviyeye düşürmek açısından oldukça önemlidir. Akış debisinin gerçekçi bir şekilde tahmini için ise akış katsayısının gerçekçi bir şekilde hesaplanması gerekir. Güncel literatürde akıș katsayısının modellenmesi için önerilen çeşitli yaklaşımlar mevcuttur. Fakat bunların çoğu kara-kutu yöntemlere dayanmaktadır ve bu nedenle genelleştirilemezler. Dolayısıyla bu çalışmada, Murat havzasının akış katsayısının modellenmesinde, olayın fizik yönünü de dikkate alan bulanık SMRGT yöntemi tercih edilmiștir. Bilindiği üzere akıș katsayısı havzanın sabit (topografya, yüzey kaplaması, zemin türü v.b) ile dinamik (meteorolojik, hidrolojik v.b.) değişkenlerini kapsamaktadır. Burada, sadece meteorolojik akış katsayısı belirlenmiş ve bunun için de sadece sıcaklık ve rüzgâr değișkenleri kullanılmıștır. Veriler Devlet Meteoroloji Bölge Müdürlüğü'nden temin edilmiștir. Elde edilen model sonuçları ölçüm verileri ile karşılaştırılmıştır. Karşılaştırmada maksimum, minimum, ortalama, standart sapma, değişim katsayısı ve çarpıklık katsayısı gibi temel istatistik büyüklükler, ortalama mutlak rölatif hata, saçılma diyagramı ve zaman serisi grafikleri kullanılmıştır. Sonuç olarak, SMRGT modelinin gerçekçi sonuçlar verdiği ve meteorolojik akış katsayısının belirlenmesinde güvenle kullanılabileceği söylenebilir.
\end{abstract}

\begin{tabular}{|c|c|}
\hline ARTICLE INFO & ABSTRACT \\
\hline Article history: & \multirow{6}{*}{$\begin{array}{l}\text { Since the global climate changes exist, today, floods can be accounted among the most important hydraulic and } \\
\text { hydrological problems of world. Extreme urbanization, concrete structures, and asphalt roads are the most } \\
\text { important factors that increase the impermeable zones and the flood flow. Estimating the flow in advance will } \\
\text { minimize the potential loss of both life and properties. Realistically determining the flow coefficient, which is } \\
\text { the most effective factor on flood flow, the existing problems will be eliminated to a considerable extent. There } \\
\text { are many techniques, which can be found in the existing literature, offered for modeling flow coefficient. } \\
\text { However, the most of them base on the black-box type methodologies and they cannot be generalized } \\
\text { Therefore, in this study, a new approach namely Fuzzy SMRGT Method, which considers the physic of the } \\
\text { event, has been preferred. The data, which contains the daily measurements of both temperature and wind speed, } \\
\text { were obtained from the Regional Directorate of Meteorology. The model results were compared with the real } \\
\text { data. For comparison, basic statistical magnitudes such as maximum, minimum, mean, standard deviation, } \\
\text { coefficient of variation and coefficient of skewness and mean absolute relative error, scattering diagram, and } \\
\text { time series graphs were used. As a result of the comparison, it can be said that the results of the SMRGT are } \\
\text { quite realistic and can be used confidently in determining the meteorological flow coefficient. }\end{array}$} \\
\hline Received: 21 December 2020 & \\
\hline Revised: 13 January 2021 & \\
\hline Accepted: 18 Janurary 2021 & \\
\hline Keywords: & \\
\hline $\begin{array}{l}\text { Flood flow, Flow coefficient, } \\
\text { Fuzzy logic, Modelling, Fuzzy } \\
\text { SMRGT }\end{array}$ & \\
\hline
\end{tabular}

\begin{abstract}
Since the global climate changes exist, today, floods can be accounted among the most important hydraulic and hydrological problems of world. Extreme urbanization, concrete structures, and asphalt roads are the most important factors that increase the impermeable zones and the flood flow. Estimating the flow in advance will

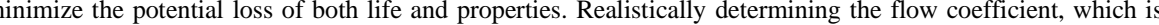
the most effective factor on flood flow, the existing problems will be eliminated to a considerable extent. There However, the most of them base on the black-box type methodologies and they cannot be generalized. Therefore, in this study, a new approach namely Fuzzy SMRGT Method, which considers the physic of the event, has been preferred. The data, which contains the daily measurements of both temperature and wind speed, of quite realistic and can be used confidently in determining the meteorological flow coefficient.
\end{abstract}




\section{Giriş}

Taşkın, son yıllarda bilim camiasının önem verdiği ulusal ve uluslararası problemlerinden biri haline gelmiştir. Özellikle son yıllarda yoğun blok yapılar, çatı örtüleri ve asfalt yollar gibi geçirimsiz yüzeyleri artıran yapıların çeşitlenerek artması geçirimsiz yüzeylerin artmasına geçirimli yüzeylerin de azalmasına neden olmaktadır. Bu durum, yağışların akışa geçen oranının gün geçtikçe artmasına dolayısıyla taşkın ve sel olaylarına neden olmaktadır. Seller beraberinde büyük kütleli katı madde getirir. Bu katı madde yerine göre köprü açıklıklarını, menfezleri veya dere yatağını doldurmaktadır. Gelen suyun debisinin de yüksek olması halinde taşkınlara neden olmaktadır. Genellikle sellere neden olan ani ve şiddetli yağışlardan kaynaklanan akışlar yüksek debili olmaktadır. Onuşluel ve Harmancıoğlu (2002)'de bu duruma işaretle "günümüz taşkınlarının en yaygın sebebi şiddetli yağışlar sirasında drenaj hatlarındaki yetersizlik sonucu ana iletim hatların veya nehir yatağının bütünüyle dolması ile oluşan yüzeysel akışın tetiklediği taşmalardır" demektedir [1]. Geçmiş medeniyetlerin taşkından korunma yapıları günümüzdekilerine nazaran sayıa daha az, alanca daha küçük ve uygulamada daha basittir [2]. Diğer taraftan yüzeysel akış alanlarının artması ve yutakların ise azalması nedeniyle eski taşkın koruma yapıları adeta işlevsiz kalmaktadır. $\mathrm{Bu}$ nedenle yeni yapılacak olan taşkın koruma yapılarının boyutlandırılmasında, projelendirilmesinde yeni ve ihtiyaca cevap verecek yöntemlerin kullanılması kaçınılmazdır. Taşkın debilerini doğru hesaplamak alınabilecek önlemler açısından büyük önem arz etmektedir. Ayrıca taşkın risk analizlerinde değerlendirilen verilerin eksik olması modelleme açısından ciddi sorunları beraberinde getirmektedir [3]. Taşkın debisinin belirlenmesinde akış katsayısı en etkili değişskendir. Akış katsayısını ise havzanın dinamik (hidrolojik özellikler gibi), sabit (topografya, eğim, havza alanı ve kaplaması, toprak geçirgenliği gibi) özellikleri ile meteorolojik özellikler (sıcaklık, rüzgâr yönü ve şiddeti, yağış şekli ve şiddeti, buharlaşma gibi) büyük ölçüde belirlemektedir. Pratikte genel olarak değişkenlerin havza üzerinde sabit alındığ modeller kullanılmaktadır [4].

Literatürde akış katsayısının modellemesine yönelik çok sayıda çalışma mevcuttur. Bu nedenle taşkın debisini tahmin etmede kullanılan ve özellikle son yıllarda sayısı çokça artan modeller bir nebze de olsa taşkın ve sel felaketlerinden kaynaklı can ve mal kaybını azaltmıștır. Bununla birlikte ne yazık ki bu çalışmalarda önerilen modellerin büyük bir çoğunluğu istatistik, stokastik, veya yapay zeka teknikleri gibi kara kutu yöntemler ile geliştirilmiştir. $\mathrm{Bu}$ tür modeller olayın fizik sebep-sonuç ilişkisini yansıtmamaktadır. Dolayısıyla tahminler gerçek değerlerden biraz daha uzakta kalmaktadır. Her modelin kendine has üslubu ve geçerliliği vardır. Ama genel olarak her modelin aşamadığı kendine has sınırları da mevcuttur ve bir modelin açığını başka bir model kapatabilmektedir. Her ne kadar Alp ve Ciğizoğlu (2010), "bir modelde havza sistemi çok sayıda parametreye ayrılırsa daha detaylı bir model geliştirilmiş olunur" diyor ise de [5], değişkenlerin sayıca fazla olması yerine olaya etkileri göz önünde tutularak her birine uygun etki faktörünü atamanın daha gerçekçi sonuçları vereceği söylenebilir. Literatürdeki en yaygın dikkatsizliklerden biri tüm bölge ve havzaların aynı şekilde işleme tabi tutulmasıdır. Hâlbuki bir havza veya bölge için gerçekçi sonuç veren bir model başka bir havza veya bölge için aynı sonucu vermeyebilir. Burada dikkat edilmesi gereken en önemli konu havzanın statik ve dinamik değişkenlerinin aynı olmayışıdır. Örneğin bir havzanın bitki örtüsü, eğimi, jeomorfolojisi, yağışı, zemin geçirgenliği, güneşe olan bakıs1, rakımı, toprak cinsi gibi birçok özellikleri bir başka havzanınkinden farklı olabilir.

$\mathrm{Bu}$ çalışma kapsamında, sıcaklık/rüzgâr etkisindeki akış katsayısı bulanık SMRGT yöntemi ile modellenmiştir. Yönteminin fiziksel tabanlı olması tüm modellerin bir nevi fiziksel açığını kapatmaya bir nebze katkı yapacağ düşünülmektedir. Yöntem aynı amaçla daha önce Karakaya (2018) tarafından havzanın yukarıda belirtilen iki özelliğine ilaveten buharlaşmayı da ekleyerek her biri için birer akış katsayısı modellenmiş sonra bunların ortalaması alınarak havzanın tüm özelliklerini dikkate alan bir akış katsayısı elde edilmiştir. Ancak Karakaya (2018) uygulama alanı olarak Şırnak kent merkezinde bulunan üniversite yerleşke alanı seçmiştir. Bu çalışmada ise daha 
büyük bir alan olarak Murat Havzası uygulama alanı olarak seçilmiştir.

Taşkın debilerini modellemeye yönelik literatürde birçok çalışma mevcuttur. Gerek ulusal gerekse uluslararasi platformda taşkınlarla ilgili çalışmalar günden güne farklı yaklaşım ile ele alınmaktadır. Hall ve Minns (1998), Bölgesel taşkın frekans analizinde yapay sinir ağlarını kullanmıştır [6]. Özcan (2017), Ayamana deresi için alakalı parametreleri ağırlıklandırmış (önem değerleri) ve çok kriterli karar verme analizini yaparak muhtemel bir taşkın durumunda etkilenecek alanları belirlemiş ve bilgi difüzyon metodunu kullanarak taşkın halinde havzanın kaçta kaçını etkilenebileceğini belirlemiştir [7]. Stronska ve ark. (1999), MIKE 11 NAM modelini kullanarak $500 \mathrm{~km}$ uzunluğunda alanın hidrolojik olarak modellemesini gerçekleştirmiş ve 49,000 km2 alanlı taşkın yayılımını FLOOD WATCH ile 2 boyutlu ortamda gözlemlemiştir [8]. Baykal ve ark.(2017), Aksu çayı havzası üzerinde birbirinden farklı birden fazla istatiksel yöntemleri kullanmıştır. Çıkan sonuçlardaki en uygun olasılık dağılımını bulmak için değerler Kolmogorov-Smirnov ile testi sınanmıştır. Dağılım grafikleri ve test sonuçlarına en uygun olan yöntemin Log-Pearson Tip III olduğu bulunmuştur [9] Barbero ve ark. (1999), MIKE FLOOD WATCH ile İtalya'daki Piemonte bölgesinde taşkınla ilgili Po nehri üzerine yaptığ 1 çalışmada toplamda $37.000 \mathrm{~km} 2$ 'lik alan çalışmasını MIKE 11 NAM modülü ile hesaplanan değerlere entegre ettirmiştir [10]. Kalken ve Ark. (2004), $6500 \mathrm{~km} 2$ ve 40 ayr1 havzaya sahip olan Kuzey Belçika'daki Scheldt kıyılarını her havza için MIKE 11 NAM modülünü kullanarak modellemiş ve MIKE FLOOD WATCH programı ile taşkın yayılım haritasını çıkarmıştır [11]. Seçkin ve ark. (2010) YSA' y1 Bat1 Karadeniz Havzası'nda kullanarak akım gözlem istasyonlarındaki maksimum akımları ve her bir istasyon için enlem, boylam, kot, alan ve tekerrür periyotları arasındaki bağlantıyı incelemiştir. YSA modelinin ÇDR ve ÇDOR'a göre muhtemel taşkını tahmin etmede daha reel sonuçlar verdiğini belirtmiştir [12]. Aydın (2018), L- momentler yöntemini taşkın frekans analizinde kullanmıştır. Uygulama alanı olarak Batı Akdeniz havzası seçilmiştir. Bu havzaya ait 50,100,1000, 10000 yıllık taşkın debileri Noktasal Taşkın Frekans Analizi ve L- momentler yöntemi ile hesaplanmıştır. Uygulama sonuçlarına göre bütün istasyonlar için yapılan hesaplamalar da mevcut iki yöntemin birbiri ile yakın sonuçlar verdiği ve birbirlerinin yerine kullanılabileceği belirlenmiştir [13].

\section{Çalışma Alanı}

Çalışma alanı seçilen Murat havzası Doğu Anadolu Bölgesinde bulunan Yukarı Firat Bölümü içinde Muş, Tunceli ile Yukarı Murat yöresini kapsamaktadır [14]. Bu sınırlar içinde Muş, Bingöl, Tunceli, Ağrı, Elazığ ve bu illere ait birçok ilçe kalmaktadır. Alanın sıcaklık ve yağış değerlerinde doğudan batıya doğru gidildikçe artış görülmektedir. Değerlerin bu yönlü değişmesi üzerinde yüksekliğin artması ve deniz etkeninin azalması yatmaktadır. Karasal iklimin etkisinde kalan havzada kışlar doğuda çok soğuk olurken yazlar sicak geçmektedir. Toplam havza alanı $25856,8 \mathrm{~km}^{2}$ olup, 8,1 milyar $\mathrm{m}^{3}$ akıma sahiptir [15].

\section{Yöntem}

\section{Yöntem (Bulanık SMRGT)}

Bulanık mantık klasik mantığa nazaran kesin sonuçtan ziyade yaklaşık sonuçlara ulaşmayı hedeflemektedir. Örneğin Klasik mantığına göre hava ya sicaktır ya da değildir. Soğuk ise sicak değildir, sıcak ise soğuk değildir. Oysa bulanık mantıkta bir sıcaklık değeri, farklı veya aynı üyelik dereceleri ile iki kümeye ait olabilmektedir. Buna göre örneğin sıcaklık uzay1, "çok soğuk", "soğuk”, "az soğuk", "1lık”, "az sicak", "sicak", "çok sicak" gibi sözel ifadeler kullanılarak çok sayıda alt bulanık küme ile ifade edilebilir. Diğer taraftan, Klasik mantıkta bir eleman bir kümeye ya aittir (aitlik; üyelik derecesi 1) veya değildir (aitlik, üyelik derecesi sifir). Oysa bulanık mantıkta bir eleman birden fazla bulanık kümeye farklı veya aynı üyelik dereceleri ile bağlı olabilmektedir. $\mathrm{Bu}$ çalışmada modelin kurulması için MATLAB'2019b programı ve araç olarak da Fuzzy Logic tercih edilmiştir.

Bulanık SMRGT yöntemi ilk olarak Toprak (2009) tarafindan önerilmiştir [16]. Yöntem, üyelik fonksiyonlarının ve bulanık kural tabanının belirlenmesinde kullanılmaktadır ve ilk olarak yazar tarafindan, açık kanal en kesitinin hesaplanmasında kullanılmış ve örnek uygulamaları verilmiştir. Sonrasında birçok 
alanda modelleme tekniği olarak kullanılmıștır. Örneğin Altaş ve ark. (2017) ve Altaş (2017), SMRGT yöntemini açık kanal akımlarında su yüzü profilinin modellenmesinde yani hidrolik alanında kullanmıştır [17]. Bayrı (2018) zeminlerin sismik açıdan sınıflandırılmasında yani geoteknik alanında kullanmıştır [18]. Akış katsayısının belirlenmesinde yani hidroloji alanında ise Karakaya (2018) aynı yöntemi kullanmıştır [19]. Diğer taraftan Çakır Aydın (2018) ise peyzaj açısından ortamın gürültü kirliliğinin sınıflandırılmasında, yani mimari alanda yöntemin bir uygulamasını vermiştir [20]. Çevre bilimindeki ilk uygulamasını kurakl1k indisinin belirlenmesi ile ilgili çalışması ile Hamidi ve ark. (2013) vermiştir [21]. Toprak ve ark. (2012) içme suyu şebekelerinde kayıp ve kaçakların tespitinde yani çevre bilimlerinde kullanmıştır [22]. Yalaz ve ark. (2013a), Yalaz ve ark. (2013b), Yalaz ve Atay (2016) bulanık doğrusal regresyon analizinde yani matematik alanında kullanmıştır [23]. Toprak ve ark. (2017) ise yöntemin avantaj ve dezavantajlarından ve pratik uygulamalarından söz etmiştir [24]. Yöntemin yeni olması, modellemede olayın fiziğini yansıtması, kolay uygulanabilir olması, gerçeğe çok yakın tahminlerde bulunması nedeniyle kısa sürede kullanım alanları artmıştır.

Bulanık SMRGT yöntemini dokuz adımda daha detaylı olarak açıklamak mümkündür:

1) Eldeki olay için bağımlı değişkeni etkileyen bağımsız değişkenler belirlenir.

2) Her bir değişken için maksimum ve minimum değerler belirlenir.

3) Üyelik fonksiyonunun şekline karar verilir (üçgen, trapez vb.).

4) Her bağımsız değişkenin üyelik fonksiyonu için bulanık alt küme sayısına karar verilir. Yöntemin kendisinden kaynaklı olarak bu sayı tek seçilmektedir. Bulanık küme sayısının fazla olması programın yükünü, az olması ise hata oranını artırmaktadir. $\mathrm{Bu}$ nedenle eldeki problemin önemi ve hassaslığına bağlı olarak bu sayı optimize edilmelidir.

5) Her bağımsız değișken için onların anahtar değerleriyle üyelik fonksiyonlarının merkezi ve genişliği belirlenir.

6) $\mathrm{Bu}$ anahtar değerler bulanık modelin girdileridir.
7) Böylece Bulanık SMRGT modeli, her bir bağımsız değişken için ilk ve son üyelik fonksiyonunun ağırlık merkezine denk gelen değer aralığı için geçerlidir.

8) Çıktıların anahtar değerleri ve bulanık kuralların sayısını veren bir tablo hazırlanır.

9) Çıktıların üyelik fonksiyonları girdilerin üyelik fonksiyonları gibi oluşturulur.

\section{Modelin Kurulması}

$\mathrm{Bu}$ çalışmada, üyelik fonksiyonları ve bulanık kural tabanının belirlenmesinde SMRGT, operatör olarak da Mamdani kullanılmıştır. Üyelik fonksiyonlarında bulanık kümelerin ilki ve sonuncusu dik üçgen ve ortadakiler ise ikizkenar üçgen seçilmiştir. Her bir bağımsız değişken için bulanık alt küme sayısı 5 olarak seçilmiştir. SMRGT yöntemine göre bu sayının tek olması tercih edilmektedir. Bulanık SMRGT tekniği gereği bağımlı değişkenin bulanık alt küme sayısı $\mathrm{N}=\mathrm{nm}$ bağıntısı ile belirlenen bulanık kural sayısına eşit olacak şekilde 25 olarak hesaplanmıştır. SMRGT'nin ilk adımı olarak akış katsayısını etkileyen tüm faktörler belirlenmiştir. Bunlar havzanın veya bölgenin veya alanın sabit değişkenleri (eğim, geçirgenlik, yüzey kaplaması) ile havzanın bölgenin veya alanın dinamik değişkenleri (yağış, rüzgâr, sıcaklık, buharlaşma vb.) olarak ifade edilebilir. Karakaya (2018) tarafindan 3 alt model kurulmuş ve bu modellerden birincisinde bağımsız değişken sıcaklık ve rüzgar alınmıştır. Çıktı olarak sadece bu iki değişkenden kaynaklanan meteorolojik akış katsayısı bulunmuştur. Diğer ikinci modelde ise eğim (S) ve arazi kullanımı $(\mathrm{G})$ girdileri kullanılarak arazi koşullarına bağlı akış katsayısı tespit edilmiștir. Üçüncü ve son alt modelde ise sızdırmazlık (I) ve doygunluk derecesi (Sr) girdileri kullanılarak bunlara bağlı akış katsayısı SMRGT yöntemiyle belirlenmiștir. Bu 3 alt modelden meydana gelen akıș katsayısı modeli Şırnak üniversitesi yerleşkesine uygulanmıştır. Bu çalışmada ise Muş kent merkezi için sadece sıcaklık ve rüzgârdan kaynaklanan akış katsayısı bulanık SMRGT yöntemiyle modellenmiştir. Akışın meydana gelmesi için elbette ki yağıș şarttır. Yağışın, sızma ve diğer kayıpların da hesaba katılması halinde havza için daha detaylı bir çalıșma olacaktır. Ancak bu çalıșmada sadece meteorolojik akış katsayısı belirlenmek istendiğinden sızma ve diğer kayıplar hariç 
tutulmuștur. Başka bir ifade ile sızma ve diğer kayıplardan sonra kalan yağışın sadece buharlaşmadan kaynaklanan akış katsayısı yüzde cinsinden tespit edilmeye çalıșılmıștır. Burada akış katsayısı 0-100 arasında değișen meydana gelen yağışın yüzdesi şeklinde ifade edilmiştir. Modellemede, Muş Meteoroloji İl Müdürlüğü'nden temin edilen ve 1988-2018 yıllarını kapsayan aylık ortalama sicaklık ve rüzgâr verileri esas alınmıştır. Daha sonra toplamda 31 yıllık verilerin yıllık ortalaması alınmıştır. Sıcaklık için min $0{ }^{\circ} \mathrm{C}$ ve mak $40{ }^{\circ} \mathrm{C}$ ve rüzgâr için min $0 \mathrm{~m} / \mathrm{s}$ ve max $5 \mathrm{~m} / \mathrm{s}$ değerleri alınmıştır. Aşağıda girdilerin (sıcaklık, rüzgâr) ve çıktının (akış katsayısı) bulanık kümeleri verilmiştir.

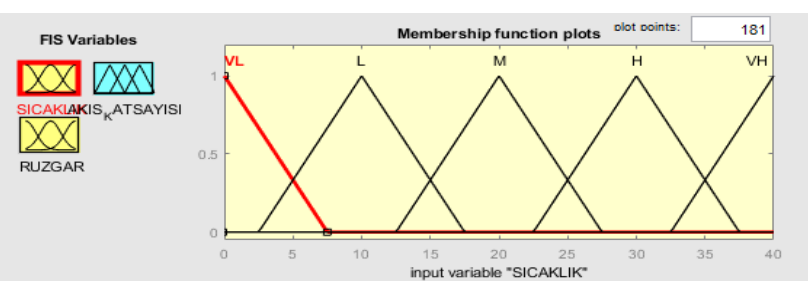

a

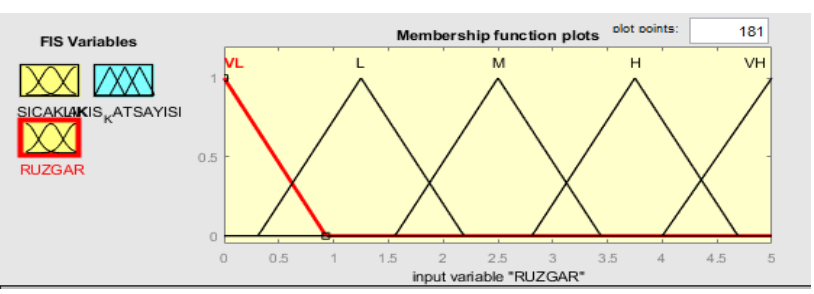

b

Şekil 1. Bă̆ımsız değişkenlere ait bulanık kümeler a) Sicaklık, b) Rüzgâr.

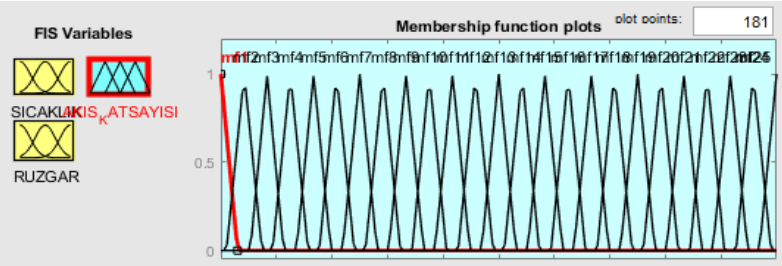

Şekil 2. Bă̆ımlı dĕgişkene ait bulanık kümeler

\section{Model Sonuçları}

Tablo 1'de, 1 kolon kural numarasını, ikinci ve üçüncü kolonlar sıcaklık değişkeninin sayısal ve sözel olarak ifade edilen bulanık alt kümelerin anahtar değerlerini, 4. ve 5. Kolonlar ise benzer şekilde rüzgâr değişkeninin anahtar değerlerini göstermektedir. 6. Kolon ise her bir kuralın ağırlık katsayısını ve takip eden iki kolon ise akış katsayısının yani çıktının sayısal ve sözel olarak ifade edilen alt bulanık kümlerin anahtar değerlerini gösterirken son iki kolon ise model sonuçlarını ve her bir kurala ait ortalama mutlak rölatif hatayı göstermektedir. Tabloya bakılırsa model sonuçları ile anahtar değerler karşılaştırıldığında genel olarak modelin iyi tahminde bulunduğu ve ortalama mutlak rölatif hatanın düşük olduğu görülmektedir. Bununla birlikte modelin toplamda ortalama mutlak rölatif hatasının (OMRH) \%32.12 oranı ile yüksek çıkmıştır. $\mathrm{Bu}$ yüksek hatanın, 21-25 nolu kurallardan kaynaklandığı tablodan açıkça okunabilmektedir. $\mathrm{Bu}$ sorunun nedeni araştırmaya değer olarak mütalaa edilmektedir. Şekil 3 ve 4'te verilen model sonuçlarına bakılırsa sıcaklık ve rüzgarın minimum değerine karşılık akış katsayısının \%99.3 gibi maksimum bir değer aldığ 1 (Şekil 3) ve sıcaklık ve rüzgarın maksimum değerine karşıllk \%0.667 gibi minimum bir değer aldığı (Şekil 4) görülecektir. $\mathrm{Bu}$ durum, sicaklık ve rüzgârın buharlaşma üzerinde etkisinin olduğunu ve buharlaşmanın yüksek olması ise akışı azalttığı gibi bir fiziksel sonucu doğrulamaktadır. Bu nedenle bu durum aynı zamanda modelin doğruya çok yakın tahminde bulunduğunun dolayısıyla gerçekçi sonuçlar verdiğinin açık bir göstergesidir. Şekil 5 'te her üç değişkenin (bağımlı ve bağımsız değişkenlerin) arasındaki ilişki üç boyutlu bir grafik ile gösterilmiştir. Bu grafik de tıpkı Şekil 3 ve 4 gibi aynı sonuçları doğrulamaktadır. Tablo 2 ise model sonuçları ile çıktının anahtar değerlerinin istatistik büyüklükleri karşılaştırmalı olarak verilmiştir. Tablodan görüleceği üzere, model sonuçları ile anahtar değerlerin istatistik büyüklükleri oldukça birbirine yakın ve aralarındaki korelasyon katsayısının da oldukça yüksek olduğu (0.99) söylenebilir. $\mathrm{Bu}$ tablo da modelin gerçekçi davrandığına dair yukarıda anılan tablo ve grafikleri desteklediğini göstermektedir. Şekil 7'de veriler ile anahtar değerlerin sirasıyla saçılma grafiği ile seri grafiği verilmiştir. Saçılma grafiği, değerlerin 45 derecelik bir doğru etrafında dağgldığı görülmektedir. $\mathrm{Bu}$ durum, modelin tarafsız davrandığını göstermesi açısından önem arz etmektedir. Diğer grafik de değerlerin oldukça birbirine yakın olduğunu göstermektedir. $\mathrm{Bu}$ da modelin gerçekçi davrandığını göstermesi açısından anlamlıdır. 
File Edit View Options

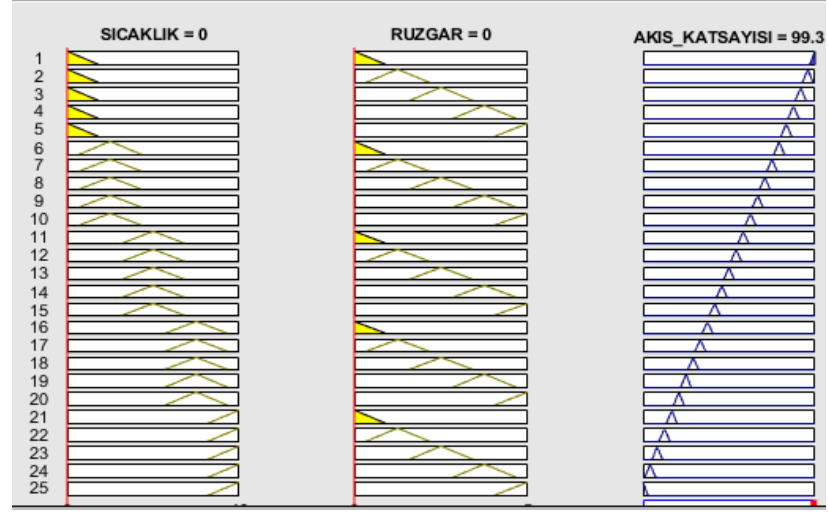

Şekil 3. Kurallarin MATLAB ile grafiksel görünümü

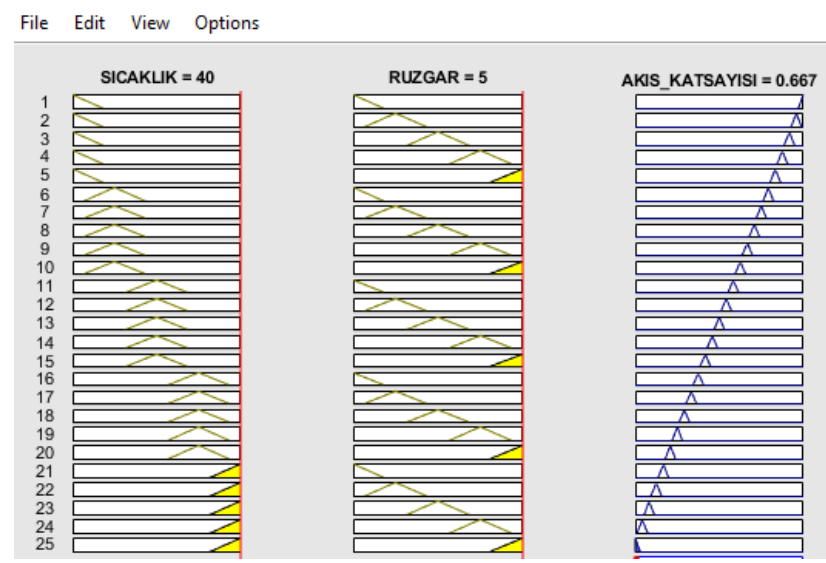

Sekil 4. Kurallarin MATLAB ile grafiksel görӥпӥтӥ

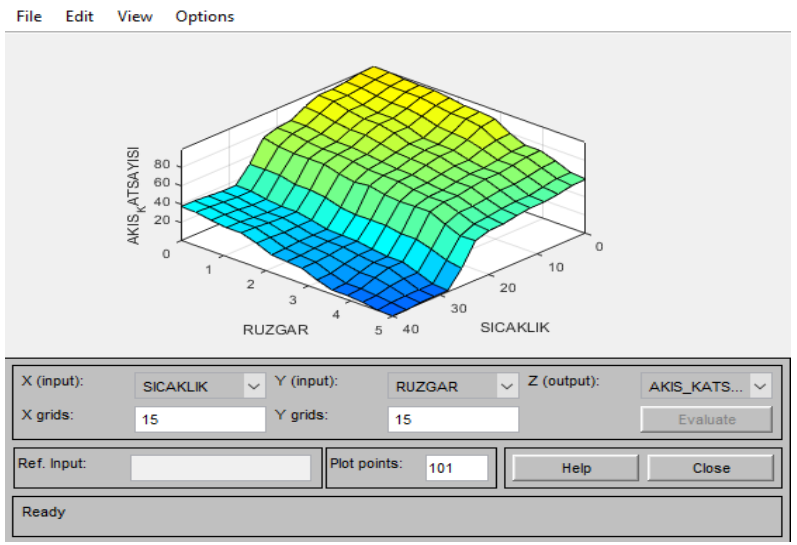

Şekil 5. Akış katsayısınin sıcaklık ve rüzgâra bağll değiş̧imi 
Tablo 1. Bulanık Kuralları Oluşturma

\begin{tabular}{|c|c|c|c|c|c|c|c|c|c|}
\hline \multirow{2}{*}{$\begin{array}{c}\text { Kural } \\
\text { No }\end{array}$} & \multicolumn{2}{|c|}{ Sicaklık ( $\left.{ }^{0} \mathrm{C}\right)$} & \multicolumn{2}{|c|}{ Ruzgar (m/s) } & \multirow{2}{*}{$\begin{array}{c}\begin{array}{c}\text { Ăğırlık } \\
\text { Katsayısı }\end{array} \\
\text { Sayısal }\end{array}$} & \multicolumn{2}{|c|}{ Akış Katsayısı (Veri) } & \multirow[t]{2}{*}{ Model } & \multirow[t]{2}{*}{ OMRH } \\
\hline & Sayısal & Sözel & Sayısal & Sözel & & Sayısal & Sözel & & \\
\hline 1 & 2.50 & Çok Düşük & 0.31 & Çok Düşük & 1.62 & 93.34 & Bir & 99.14 & 0.25 \\
\hline 2 & 2.50 & Çok Düşük & 1.25 & Düşük & 2.00 & 91.79 & İki & 95.80 & 0.17 \\
\hline 3 & 2.50 & Çok Düşük & 2.50 & Orta & 2.50 & 89.74 & Üç & 91.65 & 0.09 \\
\hline 4 & 2.50 & Çok Düşük & 3.75 & Yüksek & 3.00 & 87.69 & Dört & 87.50 & 0.01 \\
\hline 5 & 2.50 & Çok Düşük & 4.68 & Çok Yüksek & 3.37 & 86.16 & Beş & 83.43 & 0.13 \\
\hline 6 & 10.00 & Düşük & 0.31 & Çok Düşük & 6.12 & 74.87 & Alti & 79.20 & 0.23 \\
\hline 7 & 10.00 & Düşük & 1.25 & Düşük & 6.50 & 73.33 & Yedi & 75.00 & 0.09 \\
\hline 8 & 10.00 & Düşük & 2.50 & Orta & 7.00 & 71.28 & Sekiz & 70.80 & 0.03 \\
\hline 9 & 10.00 & Düşük & 3.75 & Yüksek & 7.50 & 69.23 & Dokuz & 66.65 & 0.15 \\
\hline 10 & 10.00 & Düşük & 4.68 & Çok Yüksek & 7.87 & 67.70 & On & 62.58 & 0.30 \\
\hline 11 & 20.00 & Orta & 0.31 & Çok Düşük & 12.12 & 50.25 & Onbir & 58.35 & 0.64 \\
\hline 12 & 20.00 & Orta & 1.25 & Düşük & 12.50 & 48.71 & Oniki & 54.20 & 0.45 \\
\hline 13 & 20.00 & Orta & 2.50 & Orta & 13.00 & 46.66 & Onüç & 50.00 & 0.29 \\
\hline 14 & 20.00 & Orta & 3.75 & Yüksek & 13.50 & 44.61 & Ondört & 45.80 & 0.11 \\
\hline 15 & 20.00 & Orta & 4.68 & Çok Yüksek & 13.87 & 43.08 & Onbeş & 41.72 & 0.13 \\
\hline 16 & 30.00 & Yüksek & 0.31 & Çok Düşük & 18.12 & 25.64 & Onalti & 37.50 & 1.85 \\
\hline 17 & 30.00 & Yüksek & 1.25 & Düşük & 18.50 & 24.09 & Onyedi & 33.35 & 1.54 \\
\hline 18 & 30.00 & Yüksek & 2.50 & Orta & 19.00 & 22.04 & Onsekiz & 29.20 & 1.30 \\
\hline 19 & 30.00 & Yüksek & 3.75 & Yüksek & 19.50 & 19.99 & Ondokuz & 25.00 & 1.00 \\
\hline 20 & 30.00 & Yüksek & 4.68 & Çok Yüksek & 19.87 & 18.46 & Yirmi & 20.90 & 0.53 \\
\hline 21 & 37.50 & $\begin{array}{c}\text { Çok } \\
\text { Yüksek }\end{array}$ & 0.31 & Çok Düşük & 22.62 & 7.17 & Yirmibir & 16.69 & 5.31 \\
\hline 22 & 37.50 & $\begin{array}{c}\text { Çok } \\
\text { Yüksek }\end{array}$ & 1.25 & Düşük & 23.00 & 5.63 & Yirmiiki & 12.50 & 4.88 \\
\hline 23 & 37.50 & $\begin{array}{c}\text { Çok } \\
\text { Yüksek }\end{array}$ & 2.50 & Orta & 23.50 & 3.58 & Yirmiüç & 8.30 & 5.28 \\
\hline 24 & 37.50 & $\begin{array}{c}\text { Çok } \\
\text { Yüksek }\end{array}$ & 3.75 & Yüksek & 24.00 & 1.53 & Yirmidört & 4.24 & 7.10 \\
\hline 25 & 37.50 & $\begin{array}{c}\text { Çok } \\
\text { Yüksek }\end{array}$ & 4.68 & Çok Yüksek & 24.37 & 1.00 & Yirmibeş & 0.93 & 0.28 \\
\hline & & & & & & & & Toplam & 32.12 \\
\hline
\end{tabular}


Tablo 2'den açıkça görüldüğü üzere verilerin istatistik büyüklükleri ile model sonuçlarının istatistiksel büyüklükleri birbirine oldukça yakındır. Her ikisinin arasındaki Pearson korelasyon katsayısı da oldukça yüksektir $(0,99)$. Bu iki durum, modelin başarılı olduğunu göstermektedir. Zaten Şekil 6 ve Şekil 7'de verilen saçılma diyagramı ile seri grafiği de bu sonucu desteklemektedir. Saçılma diyagramında ortalama doğrusu yatayla $45^{\circ}$ açı yapmaktadır ve değerler doğrunun etrafında oldukça yakın dağılmıştır.

Tablo 2. Model sonuçlarının veriler ile istatistiksel karşılaştırılması

\begin{tabular}{lll}
\hline İSTATIKKSEL & VERİ & MODEL \\
BÜYÜKLÜKLER & & \\
\hline Maximum & 93.34 & 99.14 \\
Minimum & 1.00 & 0.93 \\
Ortalama & 46.70 & 50.02 \\
Standart Sapma & 32.08 & 30.54 \\
Değişim Katsayısı & 0.69 & 0.61 \\
Korelasyon Katsayısı & 0.99 & \\
Çarpıklık Katsayısı & -0.05 & -0.03 \\
\hline
\end{tabular}

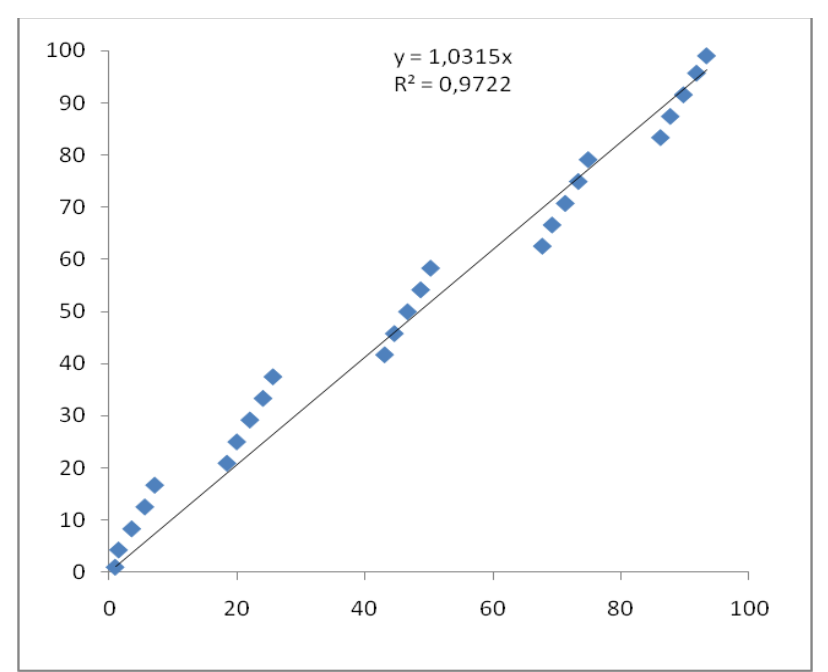

Şekil 6. Veriler ile model sonuçları arasındaki saçılma diyagramı

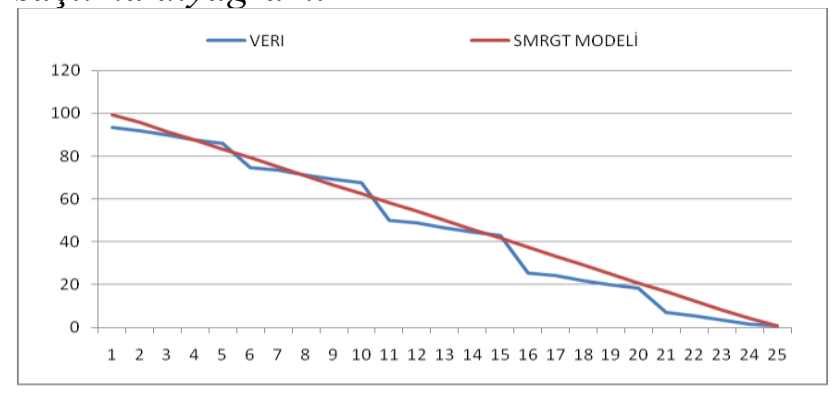

Şekil 7. Veriler ile SMRGT sonuçlarının seri grafiğ $i$

\section{Sonuç ve Öneriler}

Günümüzde geleceğe yönelik tahmin modellerinin geliştirilmesinde istatistik, olasılık ve stokastik yöntemler gibi klasik veya YSA, GA gibi modern yöntemler kullanılmaktadır. Ancak kullanılan yöntemlerin çoğu kara kutu yöntemlerdir. Kara kutu yöntemler ile geliştirilen modellerin genelleştirilmeleri beraberinde bazı sakıncaları getirmektedir. $\mathrm{Bu}$ nedenle modellemelerde genelleştirilebilir yöntemlerin kullanılması tercih edilmelidir. $\mathrm{Bu}$ çalışmada, olayın fizik sebep sonuç ilişkisini de dikkate alan ve henüz yeni olan bulanık SMRGT yöntemi Murat Havzası için meteorolojik etkenlere bağlı akış katsayısının modellenmesinde kullanılmıştır. Modelin girdileri (bağımsız değişkenler) sicaklık ve rüzgâr hızı, çıktısı (bağımsız değişken) ise meteorolojik değişkenlere bağlı akış katsayısıdır. Model sonuçları ile çıktının anahtar değerleri maksimum, minimum, ortalama, standart sapma, değişim katsayısı ve çarpıklık katsayısı gibi temel istatistik büyüklükler, ortalama mutlak rölatif hata ile ve görsel açıdan da iki farklı grafik ile karşılaştırılmıştır. Yapılan karşılaştırma sonucunda SMRGT sonuçlarının oldukça gerçekçi olduğu, Karakaya (2018)'in çıkarımlarını desteklediği ve meteorolojik akış katsayısının belirlenmesinde güvenle kullanılabileceği söylenebilir. Bununla birlikte, 21 - 25 numaralı kuralların ortalama mutlak rölatif hatayı artırdığını ve bu durumun araştırmaya değer olduğunu belirtmekte fayda görülmektedir.

\section{Bilgi}

$\mathrm{Bu}$ çalışma daha önce Muğla Sitkı Koçman Üniversitesi 10. Ulusal Hidroloji Kongresinde sözlü bildiri olarak sunulmuş olup güncelleştirilmiş ve genişletilmiştir.

\section{Kaynaklar}

[1] Sunkar, M., \& Toprak, A. Sel ve Taşkın Çalışmalarında Tarihi Veri Kaynaklarının Önemi.

[2] Onuşluel G., Harmancioğlu N.B., (2002), Su kaynaklı doğal afet: taşkın, TMH-Türkiye Mühendislik Haberleri, Sayı 420-421-422/2002/4-56, 131-132.

[3] Benn, S. (2004). Managing toxic chemicals in Australia: a regional analysis of the risk society. Journal of Risk Research, 7(4), 399-412. 
[4] Bayazıt, M., (1998). Hidrolojik Modeller, İTÜ İnşaat Fakültesi Matbaası, İstanbul.

[5] Alp, M., \& Ciğizoğlu, H. K. (2010). Farklı yapay sinir ağ1 metodları ile yağış-akış ilişkisinin modellenmesi. İTÜ DERGİSİ/d, 3(1).

[6] Hall, M.J. ve Minns, A.W., (1998). Regional flood frequency analysis using artificial neural networks, Hydroinformatics Conference, Copenhagen.

[7] Özcan, O. (2017). Taşkın tespitinin farklı yöntemlerle değerlendirilmesi: Ayamama Deresi örneği.

[8] Stronska, K., Borowichz, A., (1999). Instute of Meteorology and Water Management, Wroclaw, Kitowsk1, K., Michalık, G., Reginol Water Development Authority Wroclaw, Jorgensen, G., Van Kalken, T., Butts, M., Danish Hydraulic Institute, MIKE 11 as Flood Management and Flood Forecasting Tool for The Odra River, Poland, 3 rd DHI Software Conf., Helsingor.

[9] Baykal, T., \& Terzi, Ö. Flood Frequency Analysis of Kucuk Aksu River. Cumhuriyet Science Journal, 38(4), 639-646.

[10] Barbero, S., Rabuffetti, D., (1999). Development of a Physically Based Flood Forecasting System "MIKE Flood Watch" in the Piemonte Region, 3th DHI Software Conference, Torino, Italya.

[11] Van Kalken, T., Skotner, C., \& Madsen, H. (2004). A new generation, GIS based, open flood forecasting system. In Proceedings of the 8th National Conference on Hydraulics in Water Engineering, The institute of Engineers, Australia, ISBN (Vol. 85825 , p. 850).

[12] Seçkin, N., Güven, A., \& Yurtal, R. Taşkın Debilerinin Yapay Sinir Ağları İle Modellenmesi: Örneksel Bölge Çalışması-Batı Karadeniz Havzası. Çukurova Üniversitesi Mühendislik-Mimarlık Fakültesi Dergisi, 25(1), 45-56.

[13] Aydın, M. (2018). Batı Akdeniz Havzası Taşkın Debilerinin L Momentler Yöntemi Ve Noktasal Taşkın Frekans Analizi İle Belirlenmesi. El-Cezeri Journal of Science and Engineering, 5(1), 117-125.

[14] Erol, O. (1993). Türkiye'nin doğal yöre ve çevreleri. Ege Coğrafya Dergisi, 7(1), 13-41.

[15] Günek, H. (2006). Murat Nehri Havzasının (Firat) Su Potansiyeli ve Değerlendirilmesi. Doğu Coğrafya Dergisi, 11(16), 141-163.

[16] Toprak, ZF., (2009). Flow Discharge Modeling in Open Canals Using a New Fuzzy Modeling
Technique (SMRGT). CLEAN - Soil, Air, Water, 37(9): 742-752, 2009.10.1002 / clen. 200900146.

[17] Altaş, E., Aydin, M. C., \& Toprak, Z. F. Açık Kanal Akımlarında Su Yüzü Profilinin Bulanık SMRGT Yöntemiyle Modellenmesi. DÜMF Mühendislik Dergisi, 9(2), 975-981.

[18] Bayri G., (2018). Zeminlerin Basit Üyeli Fonksiyonlar ve Bulanik Kurallar Üretim Tekniği (SMRGT) ile Siniflandirilmasi Bitlis Eren Üniversitesi Yüksek Lisans Tezi

[19] Karakaya Derya, (2018), Akiş Katsayisinin Bulanik SMRGT Yöntemi İle Modellenmesi, Yüksek Lisans Tezi, Dicle Üniversitesi Fen Bilimleri Enstitüsü, Danışman, Prof. Dr. Z. Fuat Toprak

[20] Çakır Aydın D., (2018) İşitsel peyzajda ses çevresi memnuniyet düzeyinin bulanık mantık ile tahmin edilmesi: Diyarbakır Suriçi uygulaması İstanbul Teknik Üniversitesi / Fen Bilimleri Enstitüsü / Mimarlık Anabilim Dalı Doktora Tezi

[21] Hamidi N, Toprak ZF, Gülsever H, and Sungur M (2013), Kuraklık İndisinin SMRGT Yöntemi İle Modellenmesi, Bildiri Kitab1 pp. 311 -322, 3. Türkiye İklim Değişikliği Kongresi, TİKDEK 2013 (3rd TurkeyClimateChangeCongress), June $23-25$, 2013, ITU, Istanbul - Turkey.

[22] Toprak Z.F., Songur, M., Hamidi, N. andGulsever, H., (2012). Determination of Losses in WaterNetworks Using a New FuzzyTechnique (SMRGT), AWER Procedia Information Technology\&ComputerScience, 03(2013): 833-840.

[23] Yalaz S, Atay A, and Toprak ZF (2015), SMRGT yöntemi ile bulanıklaştırılmış veriler için bulanık doğrusal regresyon, Erciyes Üniversitesi Fen Bilimleri Enstitüsü Dergisi, 31(3), 152-158, ISSN: 1012-2354

[24] Toprak Z.F, Toprak A, Aykaç Z (2017), Bulanık SMRGT yönteminin pratik uygulamaları, DÜ Mühendislik Fakültesi Dergisi, Cilt: 8, Say1: 1, Sayfa: 123-132, Ocak 2017. 